\author{
Military Technical College \\ Kobry Elkobbah, Cairo, \\ Egypt.
}

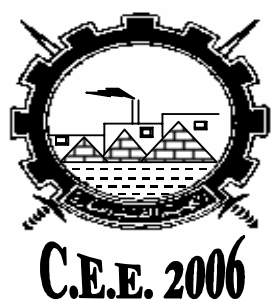

$3^{\text {rd }}$ International Conference

On

Chemical \& Environmental

Engineering

\title{
TREATMENT OF WASTE WATER FROM TNT MANUFACTURE WITH AMMONIUM CATIONIC SURFACTANTS

\author{
Shokry* Sh. A.
}

\begin{abstract}
The most serious problem occurred from the manufacture of TNT is the wastewater emanating from the plants engaged in washing of the product.

The dissolved TNT causes the well-known " pink water " discharge, which is esthetically as well as environmentally undesirable.

In this work, extensive investigations on treatment of this have been conducted using cationic surfactant under various conditions.

It was found that TNT react in aqueous solution with surfactant containing tertiary ammonium groups at $\mathrm{pH} 10-11$ at ambient temperature.

The reaction products were insoluble complex. It could be easily separated by filtration.

The dried precipitates were examined toward explosion and it burned without explosion.

The results also showed that TNT with initial concentration of till 100ppm could be quantitatively removed from waste pink water.

The used surfactant was 0.5 moles per mole of TNT in the water and the reaction time was about three hours.

According to preceding results the pink water after treatment by the recommended method in this work is suitable for reused in manufacture.
\end{abstract}

\section{KEY WORDS}

Pink water, Cationic surfactant, Foaming method of treatment, TNT complex

\footnotetext{
* Director of QC \& QA sectors in Abu Zaabal Company for Speciality Chemical.
} 


\section{INTRODUCTION}

Disposal of TNT and its degradation products from manufacturing plants and disposed sits present a serious and potentially hazardous environmental problem. A single manufacturing plant can generate as much as 500.000 gallons of wastewater per day contain TNT as well as other nitro compounds. All these wastewater are disposed of by discharging them into rivers or streams [1 ].

All TNT plants removed the undesired isomers and residual dinitrated toluene by treatment with aqueous sodium sulfite solution (sellite process). The spent sellite solution containing the extracted sulfonate derivative is known as red water and constitutes the major waste stream. This stream is one of three liquid wastes produced from TNT manufacture, neutralized spent acids with water and pink water. The pink water is almost acidic $(\mathrm{pH}=3)$.It contain about $150 \mathrm{ppM}$ of TNT. When this water exposed to the sunlight, it turns pink owing to photolysis of the dissolved TNT to form colored products [ 2 ]. The disposed of such water in environmental causes a serious difficulties, Since TNT is classified in weight of evidence group C, possible human carcinogen [ 3 ].

TNT poisoning lead to some symptoms, a plastic anemia, progressive loss of the blood element, server liver damage, cyanosis and bad symptoms on nervous system [4].

For the treatment of wastewater contaminated by TNT, neutralization and precipitation were found fruitless. Application of fungi to battement of pollution from TNT wastewater appeared unpromising because it failed to degrade TNT and because of amino transformation products were toxic.

Fourteen methods including distillation, reverse osmosis, carbon adsorption. Also regeneration to make water recycling. Destruction methods included aqueous phase catalytic oxidation and composting. Carbon adsorption was able to reduce TNT to part per billion levels because of their finite lifetime, break through of carbon column occurred occasionally [ 5,6,7 ].

Foam separation has been used to remove traces of dissolved organic compound such as phenols, enzymes, naphthalene derivatives, from aqueous solution [ 8 ].Removal of TNT from aqueous solutions by foam separation technique was investigated [ 9 ].

It was found that under certain conditions, the surfactant formed an insoluble complex with TNT in aqueous solution. It could be separated by filtration. In this work we investigate the application of ammonium cationic surfactant for the removal of TNT from wastewater by precipitation of it from aqueous solution.

\section{2- EXPERIMENTAL}

The experimental work was carried out, first, by the application of the used surfactants on prepared aqueous solutions of pure TNT. For a practical application of the process the used surfactants were employed for the treatment of samples of wastewater produced from TNT manufacturing plant. 


\subsection{Materials}

The used TNT was supplied from AZC production plant and reunified by recrystallization from ethanol. We used two types of cationic surfactant, dodecyl triethyl ammonium bromide and hexadecyl trimethyl ammonium bromide.

\subsection{Procedure}

Purified TNT (3g) was dissolved in (20) liters of water to make solutions of 150 PPM. The solution wad stirred overnight at the desired temperature and a sample was taken for analysis of TNT. The solution was transferred to the reaction vessel, and an aqueous surfactant solution was added to give the desired molar ratio of surfactant to TNT. The used molar ratio changed from 0.8 to 3.6. After the surfactant was mixed, sodium hydroxide solution wad added until the desired $\mathrm{PH}$ was reached.

The solution was stirred continuously during the entire reaction time. The solution turned from pink to a dark color immediately. Sample were taken from the reaction mixture periodically and filtered. The precipitated black solid washed with water and dried in a vacuum. TNT contents of the filtrate were determined.

For a practical application of the process, the preceding procedure was used in another runs where the aqueous solution of TNT was replaced by actual wastewater from our production plant. In these runs TNT contents in the filtrate were determined and total organic carbon (TOC) is also determined in the filtrate.

Melting point of the black precipitate was determined; it was also treated with acids and bases to cheek its revent to TNT again. The explosive reactivity of the black solid was determined using impact and frection tests.

\subsection{Analysis}

TNT contents were determines using HPLC chromatography. The used apparatus was HP 1080 B liquid chromatograph, Hewlett Packard and UV detector in the wavelength range of $0-432 \mathrm{~nm}$. Manual injection by syringe. The used column type was ODS2 $250 X 4.6 \mathrm{~mm}$ ss spherisorb $5 \mu \mathrm{m}$. The used Mobil phase mixture is methanol - water (50:50), one $\mathrm{ml} / \mathrm{min}$ flow rate, temperature of methanol - water were $40 \mathrm{C}, 80 \mathrm{C}$ respectively, attenuation and slope sense were 7 and 1 respectively. Maximum column pressure was 400 bars. UV lamp was at wavelength of $254 \mathrm{~nm}$ [10].

The slope size was $20 \mu \mathrm{l}$. The standards at known concentration of TNT were prepared using pure compounds and calibration curve was constructed. Total organic carbon (TOC) was determined using A Beckman model No.915 A carbon analyzer.

\section{RESULTS AND DISCUSSION}

The typical results summarized in table and figure 1 showed the effect of using dodecyl triethyl ammonium bromide upon the removal of TNT from its aqueous 
solution. The initial concentration of TNT was $140 \mathrm{ppm}$ and the used Ph was10. The results showed that TNT could be reduced to about 1 ppm in 5 hours when the molar ratio of the surfactant to TNT was 3.6.

Table 2 and figure 2 showed the results of using hexadecyl trimethyl ammonium bromide to remove TNT from its aqueous solution. The results showed that at the same conditions of TNT initial concentration molar ratio of surfactant to TNT and $\mathrm{pH}$ value the reaction time was shortened to only 4 hours to reach TNT concentration of less than $1 \mathrm{ppm}$ (0.9 ppm).

Table 3 and figure 3 showed the effect of the pHupon the removal of TNT from its aqueous solution using hexadecyl trimethyl ammonium bromide, which was most effective in the treatment. The used molar ratio of surfactant to TNT was 0.8 and $\mathrm{pH}$ value was varied between 10 and 11 .

The results showed that the higher $\mathrm{pH}$ (11) gives better effect on the reaction efficiency.

The results in table 4 show that the cationic ammonium surfactant which was most effective to remove TNT by precipitation from aqueous solution, gives the same effect when it used in the treatment of actual wastewater.

The initial value of TNT concentration in the waste water was $100-110$ ppm, The molar ratio between hexadecyl trimethyl ammonium bromide and TNT varied between 0.5 and 0.9 and the used $\mathrm{pH}$ was about 11 .

It is clear from the table that, under these described conditions above the TNT was quantitvely removed from the wastewater in about 30 minutes.

The results also showed that the melting point of the black solid produced from the treatment reaction was found to be about $160 \mathrm{C}$ and it had no any explosive characteristics. From the preceding results, we can reach safely to the conclusion that, the ammonium cationic surfactant was most effective to remove TNT by precipitation from waste water (pink water) The postulated mechanisms for the treatment can be explained as follows: surfactant molecules dispersed in a liquid in an aggregate called micelle, this process of forming micelles is known as micellization. In water the hydrophilic (heads) of surfactant molecules are always in contact with water. However, the hydrophobic (tails) of surfactant molecules have less contact with water. Micelles only from when concentration of surfactant is greater than critical micelle concentration (CMC), and temperature of the system are greater than critical micelle temperature $[11,12,13]$.

Concerning TNT, it has limited solubility in water ( $150 \mathrm{ppm})$ at room temperature. It reacts with strong bases, forming colored solution. The colored solution has been interpreted by the formation of the intermediate 2,4,6 trinitrobenzyl anion (TNT ${ }^{-}$) [9] as shown from the following equation:<smiles>Cc1c([N+](=O)[O-])cc([N+](=O)[O-])cc1[N+](=O)[O-]</smiles> 
It was found by Bernasconi [14] that the reaction of TNT in basic solution under condition of excess TNT form what we called Jonovsky complex as follows :

OPN

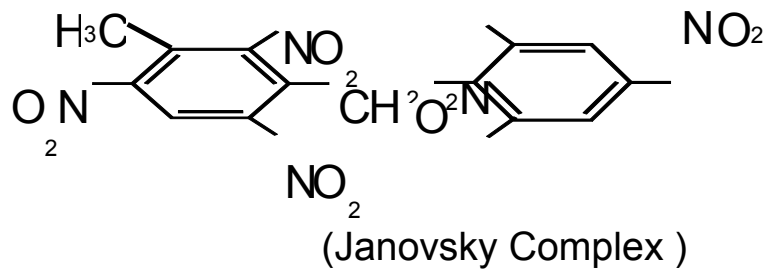

When the ammonium cationic surfactant was used, the TNT in the aqueous solution preferentially soluble in the micellar phase greatly increased and the reaction rate of the TNT with the $\mathrm{OH}$ - at the micelle aqueous interface is enhanced.

We believe that the reaction of TNT with the surfactant - NAOH system can be involved as follows

$$
\begin{aligned}
& \text { Surfactant }\left(\mathrm{R}_{4} \mathrm{~N}^{+} \mathrm{Br}^{-}\right)+\mathrm{NaoH} \longrightarrow \mathrm{R}_{4} \mathrm{~N}^{+} \mathrm{OH}^{-}+\mathrm{NaBr} \\
& \mathrm{TNT}+\mathrm{R}_{4} \mathrm{~N}^{+} \mathrm{OH}^{-} \longrightarrow \mathrm{TNT}^{-}+\mathrm{R}_{4} \mathrm{~N}^{+}+\mathrm{H}_{2} \mathrm{O} \\
& \mathrm{TNT}^{-}+\mathrm{TNT}^{-} \longrightarrow\left(\mathrm{TNT}-\mathrm{TNT}^{-}\right. \\
& \text {(Janovsky Complex) } \\
& (\mathrm{TNT}-\mathrm{TNT})^{-}+\mathrm{R}_{4} \mathrm{~N}^{+} \quad \longrightarrow \quad\left(\mathrm{TNT}-\mathrm{TNT}^{-} \mathrm{NR}_{4}{ }^{+}\right. \\
& \text {(black precipitate) }
\end{aligned}
$$

Thus when the pink water was treated with cationic surfactant- $\mathrm{NaOH}$, the TNT was precipitated as the complex (TNT-TNT) $)^{-}$(surfactant) ${ }^{+}$.

\section{CONCLUSION}

From the preceding results, we can reach safely to the conclusion that, the ammonium cationic surfactant was most effective to remove TNT by precipitation from waste water (pink water) 


\section{REFERNCES}

[1] Yinon, j. "Toxicity and metabolism of explosives", ERC Press, U.S.A. (1990).

[2] Sublette,K.L., guk,C.I., " prorphrin - catalyzed reduction of nitro aromatics for treatment of pink water ", applied biochemistry and Biotechnology. Part a. vol. 45-46 (spring) p.861-870, (1994).

[3] Review of the Armys Health Risk Assessments for oral Exposure to six chemical warfare Agents. Board on Environmental studies and Toxicology, Washington D.C. National Academy press, NRC (1999).

[4] Martin,J.L., kokjohn, T.A. and Comfort, S.D. " Microbial degradation of TNT by pseudomonas savastanoi", Conference of Hazardous water Research (1995).

[5] James,D.R., " Treatment method for remediation of nitro aromatic explosives " water research Journal Vol. 35 NO. 9 , (2005).

[6] Chitra lojagopal etal. "Development of adsorption removal process for treatment of explosives contaminant wastewater using activated carbon " Journal of hazardous material , Vol 87, (2001).

[7] Lewist, N. C. and Crawford R.," Bioremediation of soils Contaminated with explosives", Jour of Env. Mang. 70:291-307, (2004).

[8] Okamoto,Y. and Jehou, E. " Foam separation process" chapter in " hand book of separation Techniques " McGraw Hill book Co. New York, NY, (1979).

[9] Lynch,J.C., Myers,K.F. and Brannon,T.M. " Effects of PH and temperature on aqueous solubility and dissolution rate of TNT, RDX and HMX". J.CHEM. Eng. Data. 46 1549-1555,(2001).

[10] Jenkins,T.F., walsh,M.E., Bauer,C.F. and Grant,C.L. " liquid chromatographic method for determination of extractable nitro aromatic and nitramine residues in soil " J. Assoc. of Anal. Chem. Vol 72, P.890-899, 1989

[11] Fendler,J.H. and Fendler, E.J. " catalysis in micellar and Macromolecular system " Academic Press. New York chapter 3, pp. 1-55,(1975).

[12] Croce, M. and okamoto, Y., " cationic micellar catalysis of aqueous alkaline hydrolysis of 1,3,5 triazo 1,3,5-trinitrocyclohexane" J-org CHEM 44:2100-2103, (1979).

[13] Guha,S. and Jaffe, P.R.," Bioavailability of hydrophobic compounds phase of surfactants partitioned into micellar" Environ . Sc. Techno 30:1382-1391,(1996).

[14] Bernasconi, C.F., J.Am. chem. Soc. 92,129, (1970). 
Table 1. Removal of TNT From aqueous solution bydodecyl triethyl ammonium bromide

\begin{tabular}{|c|c|c|c|c|c|}
\hline \multirow{2}{*}{$\begin{array}{c}\text { Molar ratio of } \\
\text { surfactant/TNT }\end{array}$} & \multicolumn{5}{|c|}{ Concentration of TNT (ppm) } \\
\cline { 2 - 6 } & $1 \mathrm{~h}$ & $2 \mathrm{~h}$ & $3 \mathrm{~h}$ & $4 \mathrm{~h}$ & $5 \mathrm{~h}$ \\
\hline 0.8 & 51 & 19.1 & 11.1 & 8.9 & 8.6 \\
\hline 1.6 & 15 & 8.6 & 6.8 & 5.1 & 4.7 \\
\hline 2.4 & 4.7 & 6.7 & 5.6 & 4.7 & 4.1 \\
\hline 2.8 & 5 & 4.8 & 4.1 & 4 & 3.8 \\
\hline 3.2 & 3.8 & 3.7 & 3.5 & 3 & 2.8 \\
\hline 3.6 & 3.4 & 3.2 & 2.6 & 2 & 1 \\
\hline
\end{tabular}

- initial concentration of TNT = 140 ppm

- $\mathrm{pH}=10$

Table 2. Removal of TNT From aqueous solution by Hexadecyl trimethyl ammonium bromide

\begin{tabular}{|c|c|c|c|c|c|}
\hline \multirow{2}{*}{$\begin{array}{c}\text { Molar ratio of } \\
\text { surfactant/TNT }\end{array}$} & \multicolumn{5}{|c|}{ Concentration of TNT (ppm) } \\
\cline { 2 - 6 } & $\mathbf{1 h}$ & $\mathbf{2 h}$ & $\mathbf{3 h}$ & $\mathbf{4 h}$ & $\mathbf{5 h}$ \\
\hline 0.8 & 47.3 & 40.1 & 35 & 33 & 30 \\
\hline 1.6 & 21 & 15.1 & 13.8 & 9 & 7.7 \\
\hline 2.4 & 15.4 & 7.5 & 5.2 & 2 & 1.8 \\
\hline 2.8 & 10 & 4.7 & 3.7 & 1.7 & 1.3 \\
\hline 3.2 & 9.9 & 4.3 & 3.1 & 1.3 & 1.1 \\
\hline 3.6 & 6.3 & 4 & 3 & 0.9 & 0.8 \\
\hline
\end{tabular}

- initial concentration of TNT $=140 \mathrm{ppm}$

- $\mathrm{pH}=10$

Table 3. Effect of Ph on the Removal of TNT by Hexadecyl trimethyl ammonium bromide

\begin{tabular}{|c|c|c|c|}
\hline \multirow{2}{*}{$\mathbf{P h}$} & \multicolumn{3}{|c|}{ Concentration of TNT (ppm) } \\
\cline { 2 - 4 } & $\mathbf{3 h}$ & $\mathbf{4 h}$ & $\mathbf{5 h}$ \\
\hline 10 & 14 & 9.8 & 8.6 \\
\hline 10.4 & 6.8 & 4.7 & 4.1 \\
\hline 10.7 & 4.1 & 4 & 3.8 \\
\hline 11 & 3.7 & 3.5 & 3 \\
\hline
\end{tabular}

- initial concentration of TNT $=140 \mathrm{ppm}$

- molar ratio of surfactant/TNT = 1.5 
Table 4. Removal of TNT From wastewater by

Hexadecyl trimethyl ammonium bromide

\begin{tabular}{|c|c|c|c|c|}
\hline \multirow{2}{*}{$\begin{array}{c}\text { Molar ratio } \\
\text { surfactant/TNT }\end{array}$} & \multirow{2}{*}{$\begin{array}{c}\text { Initial } \\
\text { concentration of } \\
\text { TNT (ppm) }\end{array}$} & \multicolumn{3}{|c|}{$\begin{array}{c}\text { Concentration of TNT } \\
\text { (ppm) }\end{array}$} \\
\cline { 3 - 5 } & 110 & $\mathbf{0 . 5 h}$ & $\mathbf{2 h}$ & $\mathbf{3 h}$ \\
\hline 0.5 & 100 & 10 & 2 & 0.1 \\
\hline 0.6 & 110 & 0.19 & 0 & 0 \\
\hline 0.7 & 110 & 0.1 & 0 & 0 \\
\hline 0.8 & 100 & 0.5 & 0 & 0 \\
\hline 0.9 & & & & \\
\hline
\end{tabular}

Table 5. Results of TOC during the treatment of wastewater by Hexadecyl trimethyl ammonium bromide

\begin{tabular}{|c|c|c|c|c|}
\hline Molar ratio & Initial value of & \multicolumn{3}{|c|}{ TOC (ppm) } \\
\cline { 3 - 5 } surfactant/TNT & TOC & $\mathbf{0 . 5 h}$ & $\mathbf{2 h}$ & $\mathbf{3 h}$ \\
\hline 0.5 & 119 & 30 & 22 & 19 \\
\hline 0.6 & 139 & 40 & 45 & 40 \\
\hline 0.7 & 145 & 50 & 38 & 59 \\
\hline 0.8 & 155 & 52 & 34 & 58 \\
\hline 0.9 & 235 & 58 & 60 & 59 \\
\hline
\end{tabular}




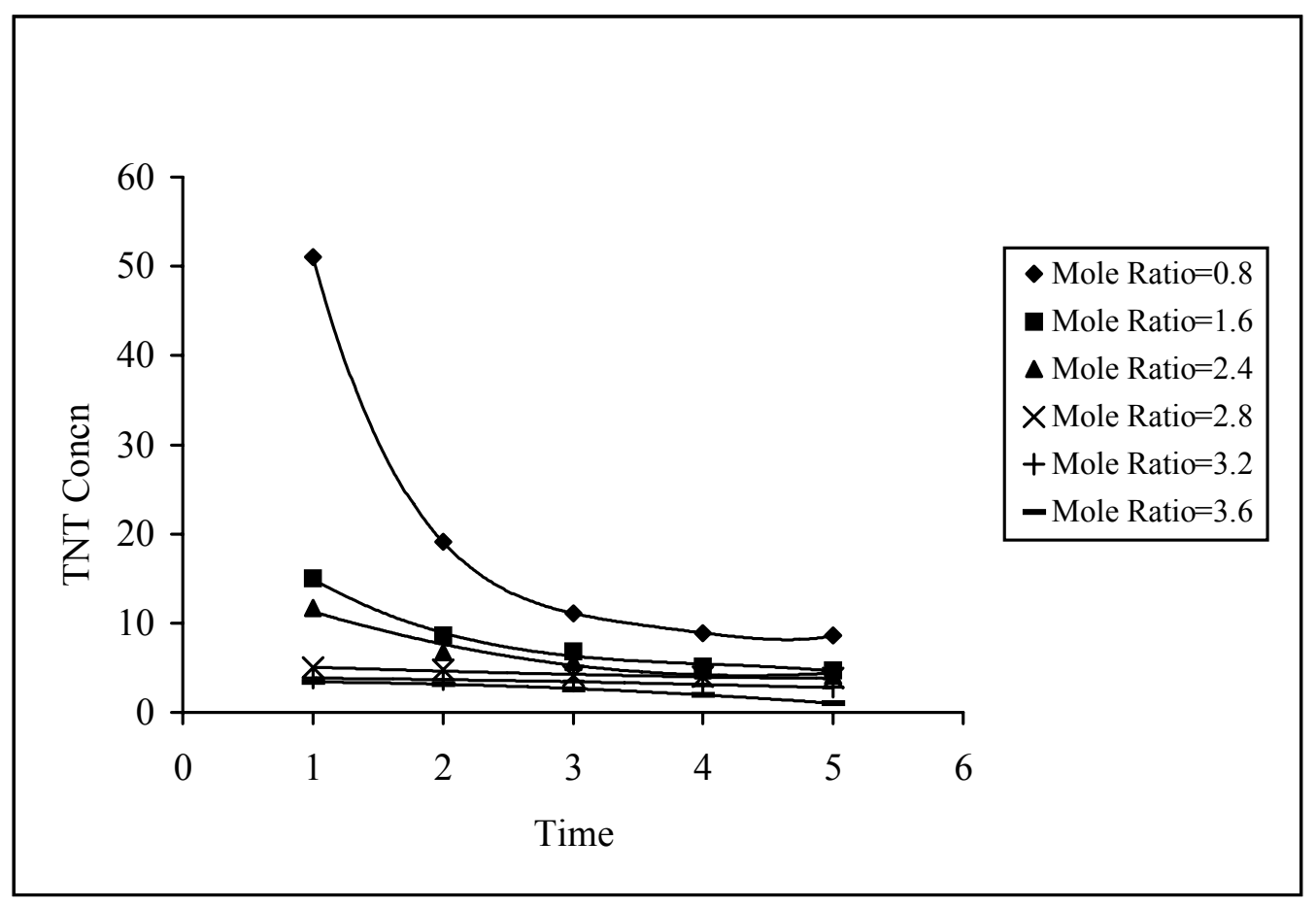

Fig. 1 Removal of TNT by dodecyl triethyl ammonium bromide

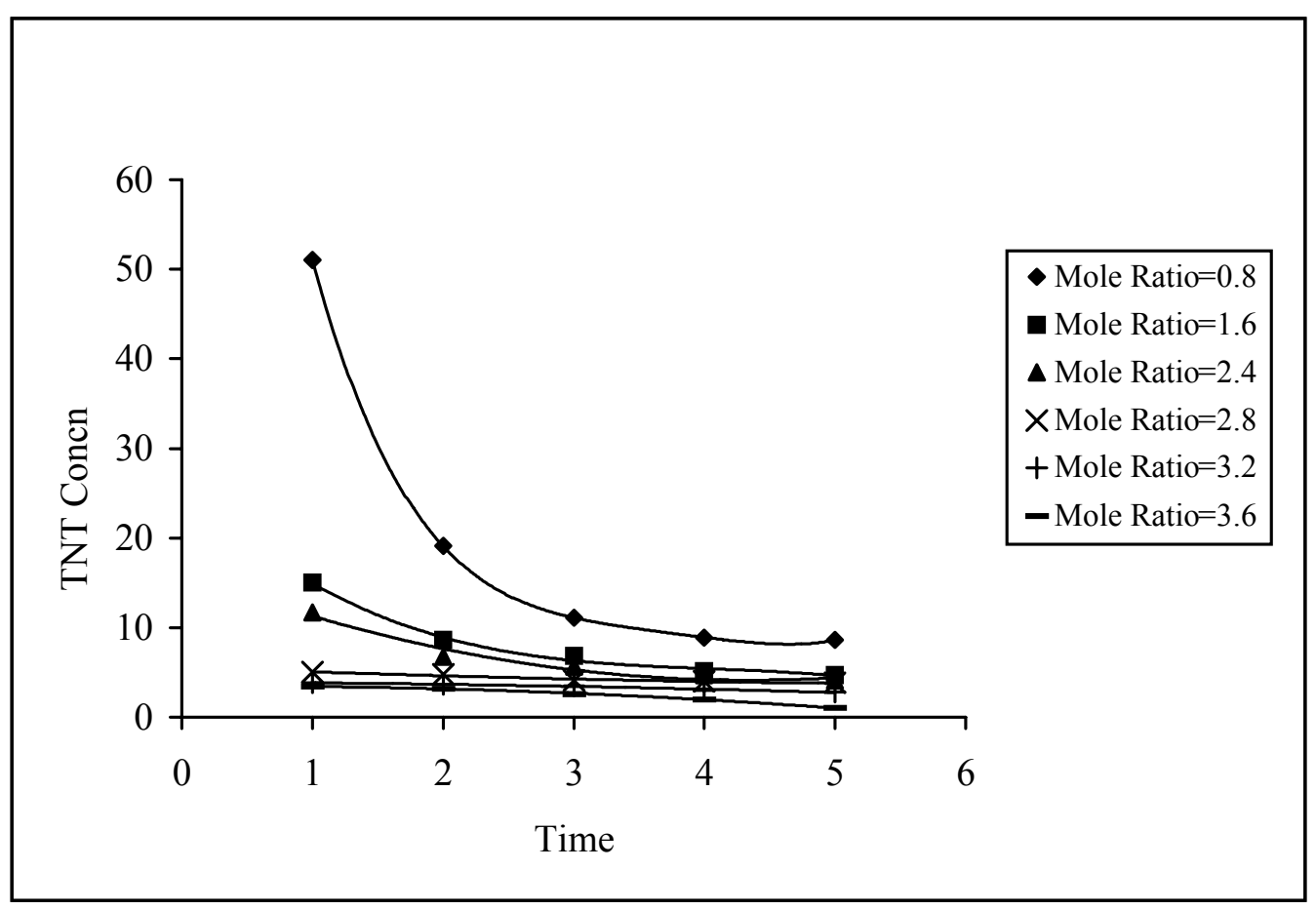

Fig.2 Removl of TNTby Hexadecyl trimethyl ammonium bromide 


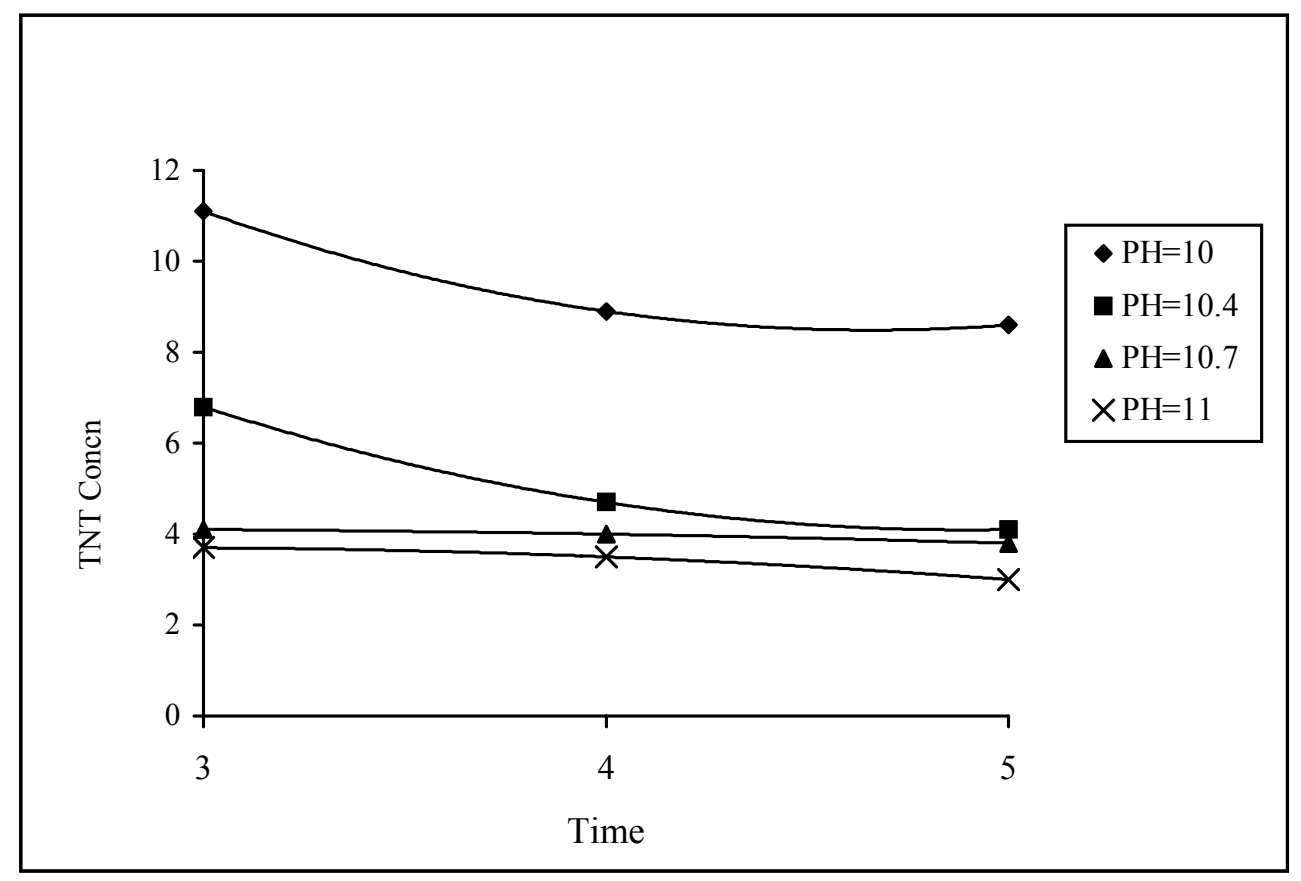

Fig. 3 Effect of pH on the removal of TNT by Hexadecyl trimethyl ammoniumbromide 